\title{
Niche Underground: Media, Technology, and the Reproduction of Underground Cultural Capital
}

\author{
Tamas Tofalvy
}

\begin{abstract}
INTRODUCTION
“...This very topography of popular music in terms of underground versus overground, margins versus centre, has been steadily dissolved this decade, partly because of the web and partly because of the economic upheavals that have beset the music industry"-wrote Simon Reynolds (2009) in an essay for The Guardian. Indeed, in recent popular and scenic discourses, and cultural criticism, there is a frequently recurring narrative, according to which unlimited access made possible by the Internet and digital platforms have, in fact, already eliminated the concept of the underground. This is because music that may be heard by practically anyone can no longer be called underground (see also Graham 2010b).

Inspired partly by this contemporary discourse, in this chapter I wish to analyze the notion of the underground, in the interrelated contexts
\end{abstract}

T. Tofalvy $(\otimes)$

Department of Sociology and Communication, Budapest University of Technology and Economics, Budapest, Hungary

(C) The Author(s) 2020

T. Tofalvy and E. Barna (eds.), Popular Music, Technology, and the Changing Media Ecosystem, Pop Music, Culture and Identity, https://doi.org/10.1007/978-3-030-44659-8_4 
of media technologies and sociocultural dynamics of collectivities organized around music. My argument follows two main tracks. On the one hand, I discuss how, in different technological, social and scenic contexts, the meaning and use of the underground may change over time; yet how the reproduction of subcultural capital maintains an ever-changing underground. On the other hand, I attempt to theorize and historicize the notion of the underground, by using, among others, theoretical tools borrowed from the Bourdieusian-Thorntonian approach of subcultural capital (Thornton 1996), and the approach I would term "cultural technology studies" (practiced by authors such as Gitelman 2006; Marvin 1988; Jackaway 1995; Sterne 2012; Baym 2010; and presented by Paolo Magaudda's work on scenic infrastructure in the present volume; Magaudda 2020). By doing so, my aim is to better integrate one of the most widely used terms relating to popular music, which is nevertheless rarely reflected upon, into the methodological realm of popular music studies, in order to gain a better understanding of a central issue in the field: the formation, hierarchical organization, and symbolic creation of niche cultures.

\section{WHAT IS UNDERGROUND?}

The origin of underground as a term and concept is similar to the other keyword in describing musical communities, namely the scene, in that initially it appeared in the political and subcultural, rather than academic discourse (while scene was introduced by music journalists). However, they also differ in the sense that while the concept of the scene was met with an enthusiastic response by scholars, and a growing number of academic papers attempted to conceptualize, theorize, develop it over the past decades (Straw 1991; Hodkinson and Deicke 2007)—as well as debating and questioning it (see Hesmondhalgh 2005) — ethnographic studies on underground communities (Thornton 1996; Fikentscher 2000; Chatterton and Hollands 2003; Matsue 2009; Panuzzo 2010) rarely focus on the conceptualization of the term underground itself.

This is probably one of the reasons why the first two book-length studies on the underground state that the notion has not been paid enough attention so far. Sean Francis Cashbaugh, in his dissertation on the cultural history of political and art underground in the United States, calls the underground an "undertheorized realm" (Cashbaugh 2016, 35), and 
Stephen Graham “a desperately neglected realm of musical activity” (Graham 2016, viii) in his work Sounds of the Underground, which was the first book-length academic attempt to theorize the concept and put it into a historical perspective. According to Graham's approach, underground is closely knit with the notions of fringe, ultra-marginality, noncommercialness, and radical aesthetics, among others:

I'm writing specifically about noncommercial forms of music that exist in a kind of loosely integrated cultural space on the fringes and outside mainstream pop and classical genres. What I'll call "underground" musical forms - noise, improv and extreme metal but also fringe practices like post-noise experimental pop and even some kinds of sound art - share a world of practitioners burrowing away independent of mainstream culture. They may be trying to resist that culture politically, but they might also just be satisfying themselves by making music for small audiences and little to no profit. My argument here is that due to shared practical, musical, and in many cases, political allegiances, these practices can be described collectively using the guiding metaphors of the "underground" and the "fringe." (Graham 2016, vii-viii)

Besides the term fringe, which Graham prefers to use, several other notions turn up in both academic literature and public discourse as alternatives or complements to underground. The most widespread attributes are probably the nonofficial (Hagen and DeNora 2011) or unofficial, counter-culture (Klaniczay 2003), avant-garde (Graham 2010a), indie (Hesmondhalgh 1999), or DIY (Bennett and Guerra 2019), which emphasize different aspects of subcultural activities. Such notions as nonofficial, alternative, or counter-culture indicate an outsider stance or opposition to majority culture and the aesthetic and political mainstream through emphasizing otherness, independence, or active rebellion. In some cases-avant-garde and indie could be examples here-they may not only signify something "different" or "independent," but rather a specific style of music. The concept of counter-culture is much more clearly politically charged and refers today mostly to the attitudes, aesthetic and political views related to the movements of 1968 in Europe and the reinterpretations of related views or sentiments. (For further readings on the relationship of the indie, the alternative and the underground, see Matsue 2009; Barna 2012; Szemere 2001.) 
Another concept that may be useful as a tool in approaching the notion of the underground is niche (Anderson 2006; Jenkins 2006). As opposed to the notions listed above, niche originates in consumer culture and markets research (Schaefers 2014). Niche cultures-highly specialized and selective, narrow markets, or cultural segments organized around particular tastes-signify an important distinction between simply "less popular" and carefully targeted products with deliberately narrow audiences in the domain of the cultural industries. Since underground genres or artists typically attract smaller audiences than popular genres, but not necessarily smaller than a merely relatively unsuccessful pop music performer, the sheer size of an audience or scene underdetermines the underground nature of a niche collectivity. An underground genre could form a "complete" genre or scene in itself-drone would be such an example, operating with long-held noises and extremely slow-motion guitar effects, or even experimental music and noise, which do not have any trends that may be called mainstream. However, in most cases, variations of a genre span the most diverse levels of popularity, from niche interest to mainstream. For instance, thrash metal, house, drum ' $\mathrm{n}$ ' bass and techno (Vitos 2012) have had their own popular, mainstream performers, alongside underground trends known only by a very few. These frequently wander from one register to another depending on the concurrent context.

Graham (2016) himself emphasizes that providing a strict definition of underground is practically impossible. Partly because of the heterogeneity of different (musical and non-music-related) practices that are called underground, and partly because underground is a contextual social construct, whose meaning is reformulated and reinterpreted under different sociocultural circumstances and in different historical periods. Therefore, in trying to grasp the notion of the underground, it seems more fruitful to focus not on the "what," but rather on the "how" aspect. How are niche cultures that are deemed to be underground created, recognized, and maintained, and how may the concept of the underground change by being embedded in different scenic infrastructures? In the following, partly by building on Graham's findings, I attempt to outline a brief historical overview of the continuity and change of the underground, with a view to the role of media technologies in the context of sociocultural patterns. 


\section{The First Underground: The Political and the Unofficial}

Graham $(2016,10)$ distinguishes between two chronologically distinct undergrounds based on the materiality of their distribution networks. Thus, in the earlier period, physically anchored networks were predominant (such as those based around fanzines and physical shops), while in the more recent one, web-based distribution dominates. Although the role of materiality, media and technology is indeed crucial in shaping underground practices by offering infrastructures (Magaudda 2020), in my approach, I will distinguish between three overlapping eras, focusing not only on the materiality of distribution, but also on the interaction of geographical, cultural, economic, and technological factors.

The now global concept of the underground has carried numerous layers of meaning over the past decades and in different geographical areas, such as the United States, Western Europe, and Central and Eastern Europe, which typically no longer refer to existing conditions, but rather live on as metaphors. One such layer is the name itself, the origins of which may be traced back to the postwar period, but which was first used to signify niche cultural communities opposing political regimes from approximately the 1960s. At that time, the label was synonymous with the groups confronting the concurrent political establishment, status quo, or oppression-whether in the east (Szemere 2001) or in the west (Cashbaugh 2016) - professing and voicing alternative ideas, intertwined with counter-cultural organization and occasional anti-establishment rebellion. The first wave of practices that emerged (or rather descended) as underground was products of, or reactions to, oppressive political systems. The formation of the term, the connection between its now metaphorical, once possibly literal meaning and message is clear: representatives of the culture exiled underground by the power dominant "on the surface" continued their activities — such as playing and listening to music - in a world uncontrollable and unseen by authorities (Szemere 2001). "Unofficial art. An artistic 'movement,' which neither supports nor attacks the establishment, but resides outside of it. By attacking it, it would acknowledge its existence" - as Béla Hap (1973), one of the figures of the Hungarian underground, commented on one of the (least militant) segments of the underground. This segment opposed the communist regime by completely withdrawing themselves from societal and political action. 
Boundaries between the underground and non-underground-due to authorities keeping vigilant watch over participants-were necessarily very clear at this time, and the stark differences between their technological regimes and media platforms also reflected their opposition. As, for instance, during the era of totalitarian regimes in the Central and Eastern European region, the technological means for music production, distribution, and media were uncompromisingly controlled by the state (recording studios were run by the state-owned monopolist recording company, so was vinyl manufacturing, and the only mass broadcasting media available were the state-owned radio and television [see Draganova and Blackman 2019; Szemere 2001 on the Bulgarian and Hungarian examples, respectively]). The use of those means thus clearly indicated whether a given production belonged to the state-supported mass culture or to the counter-cultural, nonofficial underground niche.

This relation of power was clearly reflected in the use and display of music technologies and media. As, for instance, releasing a vinyl LP album was possible only through the official production channels, and by bands who were favored by censorship boards, for the banned or unacknowledged musical collectives, the DIY bootlegs of underground live events remained, distributed on tapes, and later cassettes. Similarly, niche discourse on music had to remain in the underground media: While the favored bands were often featured in the (also state-owned and run) newspapers or youth magazines, underground bands were discussed in illegally printed, copied, and distributed materials called samizdat (Sükösd 2012). In the meantime, a different counter-cultural underground sphere developed in the cold war period in the United States, also characterized by opposition to power and mass cultural values (Cashbaugh 2016; Turner 2006), and manifested in various activities such as establishing self-supporting commune settlements, circulating DIY materials and organizing musical collectivities, such as the Los Angeles Free Music Society, from the early 1970s (Graham 2016).

The key concepts of the early phase of underground were illegality or semi-illegality, struggle and confrontation with power, opposition to the official political and artistic elite, devotion to alternative social ideals and the expression of those through various media; being peripheral, developing an alternative canon, transitionality, concealment, access available exclusively via the initiated. This political notion of underground continued to exist in Central and Eastern Europe until the end of communism. Yet starting roughly from the late 1960s and early 1970s, it began 
to be accompanied by another, newer concept in formation, which infiltrated the earlier underground and gradually gained ground together with western capitalism: the underground set against the cultural space called mainstream.

\section{The SECond Underground:}

\section{Against the Mainstream}

This new kind of opposition was no longer of political, but rather of economic origin. Mainstream music is released and distributed by major record labels targeted to a large, wide audience with the aim of making profit (Shuker 2001; Toynbee 2000). The underground, desiring to differentiate itself from this, began to indicate genres refusing this ambition and audiences deliberately choosing to remain unseen by the general public. The light yet expressive definition of underground attributed to Frank Zappa-"the mainstream comes to you, but you have to go to the underground"-refers to that interpretation of the notion. This oneliner implies, by emphasizing the imperative of choice, that underground assumes the active participation of listeners, in a somewhat hidden, but not completely closed environment. The key concepts of the underground in this context are voluntary separation from the mainstream (often representing, of course, the ambivalent attitudes of both denying and desiring the success of the bands who "made it"); production companies and distribution networks partially or completely independent from major labels, and some of them functioning based on non-profit business models (Hesmondhalgh 1998; Webb 2007); the conscious use of sounds, lyrics, and visuals unsaleable by the mainstream music business; and the formation and further proliferation of numerous new niche identities, genres (and subgenres), styles, and markets (Anderson 2006). The borders between the underground and the non-underground are not as clear as in the case of the political underground. Consequently, discourses on telling one from the other are flourishing. However, instead of focusing on the question of sheer access or the nature of the boundary between mainstream and underground, it seems to be more fruitful to reframe the key dilemmas of the underground-mainstream opposition within the framework of cultural capital.

In the wake of Bourdieu (1987), Sarah Thornton (1996) elaborated the concept of subcultural capital, which, in her analysis, is closely linked to the conceptual web of symbolic practices regarded as underground. 
In Thornton's interpretation, club cultures as communities of taste organized around musical preference form various hierarchies of expertise, relationships, and skills, thereby defining what is authentic or "hip" and what is not. In the discourses described by Thornton, cultural capital built upon authenticity, credibility, "realness," and other positive subcultural indicators and values, is fundamentally connected to the interpretations of underground. Therefore, what is credible and real is at the same time also characteristically truly underground, and what is truly underground is necessarily credible and cool in the context of the whole scene.

Besides the particular electronic music scene-British acid housestudied by Thornton, in virtually all ethnographic accounts of the discourses of underground communities (from hip-hop through metal to world music), we can find a similar interconnected value system of authenticity and underground existence. Participants having more underground cultural capital at their disposal occupy a higher position in the scene hierarchy, and those who have not succeeded in gathering subcultural capital have an accordingly lower position. In a social network where the greatest symbolic value is the explicit expression of an oppositional stance toward the reigning political power, but technological means are scarce-such as in the first era of underground-revolutionary, non-conformist artistic concepts gain in value, but the state of the development of media technology becomes irrelevant. Moreover, the underground perception of music spreading through illegal, copied tapes, and cassettes is further enhanced by the poor sound quality, which indicates attachment to obviously nonstate and nonofficial systems of production and distribution.

In his book Making Popular Music, Jason Toynbee writes:

The mainstream has to transcend particular communities in order to reach the largest number of people possible. It follows that in order to produce a mainstream the music industries must find musical texts and generic discourse which "fold difference in," and articulate distinct social groups together. (Toynbee 2000, 122-123, emphasis in original)

In this sense, traits of niche cultural production and consumption are exactly the opposite of mainstream production and consumption: reaching deliberately narrow audiences, emphasizing, embracing the "otherness" of the niche, and reflecting on the nature of belonging. When it comes to the accumulation of cultural capital in the age of the mainstream-opposing era, one of the most important credits in underground niche cultures is authenticity (Graham 2016). This can be 
expressed through the communication of taste, work ethic, and scenic knowledge, among other things. As Fikentscher puts it:

...underground activities, whether primarily political or cultural in nature (some are both) can be said to take place in a limited space, inhabited by a limited number of participants who may establish various mechanisms to further the longevity of their activities. One of the most common of such mechanisms is the cultivation and control of insider knowledge. Musical connoisseurship is one of the attributes of underground membership. (Fikentscher 2000, 10)

Besides shared knowledge and taste, there are other, lesser-known, but equally notable factors of achieving an authentic status in underground scenic hierarchies, such as complying with a strict work ethic (Kahn-Harris 2004; Tofalvy 2014) and consistently building scenic careers (Macdonald 2001).

Such expressions and perceptions of cultural capital are intertwined with the use-and avoidance- of certain media technologies and platforms as well. In the paradigm of the anti-commercial underground, it was neither the state, nor political power, but the dominant cultural industry players that defined what kind of media technologies served the purpose of channeling content toward mass audiences the best. Channels of mainstream media (television, radio, and print newspapers) were designed to reach mass audiences. These thus served as gatekeepers, who were reluctant to enable the distribution of any content not capable of satisfying mass audience demands. As a consequence of, or at least pendant to this strategy, in underground symbolic networks defined by opposing the mainstream, the use of the channels and platforms of mainstream media was regarded as a signifier of low cultural capital. Thus underground communication, cultural production, and consumption moved toward alternative channels. Fanzines, pirate radios, copied cassettes, DIY merchandise, early web forums, $\mathrm{p} 2 \mathrm{p}$ (peer-to-peer) networks, chat rooms and Lo-Fi recording technologies were capable of forging underground cultural capital, as niche audiences were supposed to be aware of, and value, the insider knowledge, taste, and network of personal connections behind such channels and products. With the fragmentation and accretion of available media platforms (which process began before the digitization of media, for instance with the expansion of cable television networks), this relationship between the accumulation of cultural capital and media 
technologies was about to change. Nevertheless, in the quest for scenic or subcultural authenticity, the demand for telling the experts from laypeople, authentic and inauthentic scene members, or re-evaluating canons and musical works remained unchanged. The question is, what happens to this equilibrium in the digital ecosystem? How is it possible to forge and build underground cultural capital? What are the difficulties, barriers, possibilities, spaces, and who are the ones to succeed in the new context in forging cultural capital that may be perceived as underground?

\section{The Third Underground: Niche Cultures in the Digital Ecosystem}

Spaces and norms of the online realm have gradually changed over the past decades, so in mapping out the relationship between the accumulation of underground cultural capital and the Internet, we need to consider those changes. As in the case of underground practices, instead of drawing sharp boundaries, it is more expedient to concentrate on the shifts of emphasis from the early web to the era of streaming platforms. On the early web, the most important niche cultural platforms probably were, besides Web sites, the forums, listservs, and chat rooms in which scene members could access and share contents or information related to the scene (to share music itself in that period was not quite easy), and, most importantly, could communicate with each other and maintain their social networks (Lee and Peterson 2004). This was before the ubiquity of Google searches, and although some of the early search engines already existed, neither those technologies nor the culture of online search facilitated search-driven browsing and orientation on the web. For this reason, underground niche content was literally hidden on the early web, obscure and hard to find. Partly because of this and partly because of the architecture of online spaces, it was relatively easy to maintain offline hierarchies and boundaries of scenes online, as Paul Hodkinson observed about the use of Goth forums in the 1990s:

In the unlikely event that a non-goth did subscribe to a goth discussion forum, however, the chances of their persevering for long were also relatively faint, due to the specialist and exclusive nature of discussion, and the tendency for mistrust and hostility towards outsiders (...) Consistent with this, the posting of inappropriate or ill-informed messages by those not sufficiently socialized into goth discussion-group norms was liable to 
result in being flamed. While sometimes goths found themselves on the end of such treatment, it was particularly effective in excluding perceived outsiders. (Hodkinson 2002, 180, emphasis in original)

In this early phase of the Internet, further significant platforms providing room for niche cultural exchange were the first peer-to-peer file-sharing networks, such as Napster, Audiogalaxy, DC++, Kazaa, or Soulseek. The significance of these platforms was, on the one hand, that they enabled sharing of niche music that had disappeared from the shelves of brick and mortar stores and were available only on the long tail of file-sharing networks. And on the other hand, they enabled the initiating of scenic conversations either directly between fans, or in genre- (or subgenre-) themed chat groups (as in the case of Soulseek). The sharing of digital music collections with peers, even anonymously, offered an excellent opportunity for fans to showcase their sophisticated musical taste and connoisseurship. The size and quality of the collection, the ordering of items, folders, albums, and genres - similar to the organization of a traditional, offline record collection-all offered clues for the beholders for evaluating the scenic position of the collector. (Furthermore, the potential or actual illegality of sharing underground music on peer-to-peer networks also contributed to the subsistence of a sense of belonging based on counter-cultural sentiments, as in the first, material era of underground.)

With online search coming to the forefront of online navigation and orientation, users - deliberately or incidentally-could get acquainted with online spaces they had not had the chance to see before. Still, some niche performers managed to maintain their obscurity by hiding from Google, thus persuading listeners who showed interest to find their music for themselves through hard work. One of the examples of this attitude is the case of the genre witch house, also called drag, or, in other cases, haunted house. The name of this genre, according to one origin story, does not even come from the artists, but from a Last.fm user, who suddenly began to attach this label to the music thought by them to belong to this genre. The performers, who were discussed on the pages of The Guardian, Pitchfork, Wired, and The New York Times (Colly 2010; Wright 2010; Ellis 2010), and who played gloomy electronic music assembled, among many others, from hip-hop, drone, goth and film music samples, were especially fond of using names difficult to find with search engines, composed partially or totally of symbols (such as oOoOO, S4LEM, /// /l, †††, Gr†LLGR†LL, twYIY<ght>ZoN). They 
removed their tracks uploaded to various free web storage spaces after a while to upload them on different locations, and so on; ambitious music listeners certainly had to struggle if they wanted to listen to their latest works.

Although the era of the social web (also known as web 2.0) has not brought about as radical changes regarding the democratization of the cultural industries (Hesmondhalgh 2019) as it was claimed by enthusiastic contemporary commentators and market players, it has led to a number of significant changes in the online lives of niche cultures. On the one hand, in the online music ecosystem, dominated by services such as Last.fm and MySpace, users finally had the means to legally access musical content and more platforms to discuss and comment on music and interact with peers. On the other hand, those platforms typically facilitated transparent and open interaction for various user groups and individuals, instead of supporting the maintenance of closed or secluded online spaces. For instance, Last.fm opened up the possibility for all users to get involved in categorizing ${ }^{1}$ and tagging even underground bands, regardless of the users' background and knowledge about the band or scene. Similarly, on MySpace, everyone was allowed to create an account, upload their music, or get acquainted with other users. In this online environment, niche cultures unexpectedly became exposed to mass publicity, which initiated conflicts and vigorous debates among those who deemed themselves authentic members of a given niche culture, and the commenters or users reckoned by them as intruders (Tofalvy 2014).

As the social web moved swiftly toward the streaming ecosystem (with the dominance of YouTube and Spotify), all those gestures of hiding and obscurity became difficult to realize. However, the niche nature of underground music persists-ironically, precisely because of the huge amount of options and music available on the Internet. As a result of a process of fragmentation-a growing number of services and content offered by more and more providers-a "massively parallel culture" (Anderson 2006, 184 ) is being formed. This kind of proliferation of choices, along with the scarcity of time and attention, does not restrain, on the contrary, creates niche consumption patterns.

A spectacular illustration of this tendency could be the data measuring the number of plays of songs on Spotify, which inspired the idea behind Forgotify. According to Spotify data (Kumparak 2014), 80\% of the approximately 20 million songs available (in 2013) had been listened to at least once, and $20 \%$, about 4 million tracks, had not. On Forgotify.com, 
one can play a random song-offered by the algorithm behind of the site- that has never been played before, at least on Spotify.

The bigger the selection, and the smaller the amount of attention that can be paid to an individual album or track, the more important the skills assisting orientation in the "crowded musical landscape" become, such as curation (Barna 2017) and digital literacy skills that mediate subcultural values of taste and selection. Digital skills of authentic curation and selection are not bound to the possession of music anymore, rather, they are related to fast search and navigation in the appropriate databases, and the well-timed sharing of tracks, playlists, music videos that best suit current niche trends and needs. In this environment, instead of highlighting opposition to the mainstream, emphasizing the way of sharing comes increasingly to the forefront. For the content with the promise of high cultural capital, one must continue to "go down" to the less frequently visited niche segments of the Internet. This once meant the music blogs linking to albums uploaded to file-storing services (from Megaupload to iFile), later to SoundCloud profiles, and more recently to Spotify playlists that feature the most hip and current music. Underground cultural capital was always a question of timing, too, as the everyday phrase "before it was cool" expresses aptly, indicating that one has experienced, heard, or seen something they appreciated among the first, and most certainly well before it had become appealing for the general audience. In Sarah Thornton's words: "The underground espouses a fashion system that is highly relative; it is all about position, context and timing. Its subcultural capitals have built-in obsolescence so that it can maintain its status not only as the prerogative of the young, but the "hip" (Thornton 1996, 118). In the attention economy of the fast moving online social media sphere $(\mathrm{Wu}$ 2017), emphasis shifts toward the extreme significance of precise timing: Who is the fastest to share and present the music currently authentic? What is the music that is accepted as authentic by scene members in the given moment?

Those strategies present an amalgam of practices originated in the first, and even more in the second era of underground niche cultures, providing social contexts and meanings for the accumulation of cultural capital, and ensuring that the underground remains a participatory sphere, an "intermediated space," where there are no radical divisions between musicians, labels, and audiences, and which is motivated primarily not by business interests, but the devotion of sharing niche taste and a sense of belonging (Graham 2016, 12). 


\section{CONCLUSIONS}

The belief that new media technologies, let alone the Internet, would put cultural formations to an end and disrupt the social status quo, for the better or worse, is not novel at all. This deterministic view has been present from the very beginnings of the world wide web: The Internet has been seen as the bringer of equality and democracy (Lessig 2006), later as the leveling tool for the music industry (Hesmondhalgh 2019), and also the liquidator of the underground.

Media technologies in themselves, as numerous historical examples from book printing through television to the latest online platforms show, do not necessarily eliminate pre-existing communities of knowledge and taste, nor internal needs and social demands that shape the hierarchic structures of communities. Rather, they serve as infrastructures by providing spaces for communities to interact (Marvin 1988). In this chapter, I attempted to argue for the idea that technological innovations deemed to be (with any optional prefix) "revolutionary" typically effect social configurations only within certain limits, creating new market relations in the cultural economies, channeling in already existing and persisting demands and supplies and conflicts in new ways. Applied to the particular case of the concept of the underground, this means that as long as all these social mechanisms that value hierarchies based on knowledge, taste, and authenticity exist, the accumulation of cultural capital will maintain the separation of self-reflective niche cultures even in novel infrastructural contexts.

Recent online and digital media trends indeed affected the rules of underground music networks and communities, but in a special way: transforming yet preserving the role and meaning of underground niche practices and communities. Although the birth of the underground was closely tied to counter-cultural movements, in the past (at least) four decades, this relationship has changed fundamentally, first with the dominance of the mainstream-oriented underground opposition, and more recently with the spreading of digital social media and streaming platforms, forming new underground practices, but preserving the core mechanisms of self-reflective niche cultures. As Stephen Graham (2016, 11) wrote, "the 'going to' remains," and so do the ever-changing dichotomies of center and periphery, hip and uncool, popular and unpopular, mass and niche, mainstream and underground.

Acknowledgements This paper was supported by the Janos Bolyai Scholarship of the Hungarian Academy of Sciences. 


\section{Note}

1. It is intriguing, however, that in this sense, Spotify has a shorter digital long tail than the Ecast database had back in 2004. Ecast was a company operating digital jukeboxes which were connected to a database featuring 10,000 albums, and $98 \%$ of the tracks were sold at least once per quarter, so only $2 \%$ of the songs remained unplayed-according to the "98 percent rule" (Anderson 2006, 7-8).

\section{REFERENCES}

Anderson, Chris. 2006. The Long Tail: Why the Future of Business Is Selling Less of More. New York: Hyperion.

Barna, Emília. 2012. "Articulating the (Inter) National Through Aesthetic Choices: Towards an Understanding of the Hungarian Indie Scene 20002010 in a Translocal Context." EastBound 1: 1-27.

. 2017. "The Perfect Guide in a Crowded Musical Landscape': Online Music Platforms and Curatorship." First Monday 22 (4) (April 3).

Baym, Nancy K. 2010. Personal Connections in the Digital Age. Malden, MA: Polity Press.

Bennett, Andy, and Paula Guerra. 2019. "Rethinking DIY Culture in a Postindustrial and Global Context." In DIY Cultures and Underground Music Scenes, 7-18. New York: Routledge.

Bourdieu, Pierre. 1987. Distinction: A Social Critique of the Judgement of Taste. Cambridge: Harvard University Press.

Cashbaugh, Sean Francis. 2016. "A Cultural History Beneath the Left: Politics, Art, and the Emergence of the Underground During the Cold War." University of Texas at Austin.

Chatterton, Paul, and Robert Hollands. 2003. Urban Nightscapes: Youth Cultures, Pleasure Spaces and Corporate Power. London: Routledge.

Colly, Joe. 2010. "Ghosts in the Machine." Pitchfork, May 24.

Draganova, Asya, and Shane Blackman. 2019. "A Howl of the Estranged: Postpunk and Contemporary Underground Scenes in Bulgarian Popular Music." In DIY Cultures and Underground Music Scenes, edited by Andy Bennett and Paula Guerra, 230-242. New York: Routledge.

Ellis, Warren. 2010. "On the Death of Blogging." Wired UK, November 11.

Fikentscher, Kai. 2000. "You Better Work!": Underground Dance Music in New York City. Middletown: Wesleyan University Press.

Gitelman, Lisa. 2006. Always Already New: Media, History, and the Data of Culture. Cambridge: MIT Press.

Graham, Stephen. 2010a. (Un)Popular Avant-Gardes: Popular Music and the Avant-Garde. Perspectives of New Music 48 (2): 5-20. 
2010b. "Where Is the Underground?" Journal of Music.

- 2016. Sounds of the Underground. A Cultural, Political and Aesthetic Mapping of Underground and Fringe Music. Ann Arbor: University of Michigan Press.

Hagen, Trever, and Tia DeNora. 2011. "From Listening to Distribution: Nonofficial Music Practices in Hungary and Czechoslovakia from the 1960s to the 1980s." In The Oxford Handbook of Sound Studies, edited by Trevor Pinch and Karin Bijsterveld, 440-458. Oxford: Oxford University Press.

Hap, Béla. 1973. "Halk magyar underground-kiáltvány (Silent Hungarian Underground Manifesto)." Szétfolyóirat. http://www.artpool.hu/Aczelkor/ Hap.html.

Hesmondhalgh, David. 1998. "Post-punk's Attempt to Democratise the Music Industry: The Success and Failure of Rough Trade." Popular Music 16 (3): $255-274$.

- 1999. "Indie: The Institutional Politics and Aesthetics of a Popular Music Genre." Cultural Studies 13 (1): 34-61.

- 2005. "Subcultures, Scenes or Tribes? None of the Above." Journal of routh Studies 8 (1): 21-40.

- 2019. "Have Digital Communication Technologies Democratized the Media Industries?" In Media and Society, 6th ed., edited by James Curran and David Hesmondhalgh, 101-120. London and New York: Bloomsbury Academic.

Hodkinson, Paul. 2002. Goth. Identity, Style and Subculture. New York: Berg.

Hodkinson, Paul, and Wolfgang Deicke, eds. 2007. Youth Cultures: Scenes, Subcultures and Tribes. New York: Routledge.

Jackaway, Gwenyth L. 1995. Media at War: Radio's Challenge to the Newspapers, 1924-1939. Westport: Praeger.

Jenkins, Henry. 2006. Convergence Culture: Where Old and New Media Collide. New York: New York University Press.

Kahn-Harris, Keith. 2004. "Unspectacular Subculture? Transgression and Mundanity in the Global Extreme Metal Scene." In After Subculture: Critical Studies in Contemporary Youth Culture, edited by Andy Bennett and Keith Kahn-Harris, 107-118. Basingstoke: Palgrave.

Klaniczay, Gábor. 2003. Ellenkultúra a betvenes-nyolcvanas években [CounterCulture in the Seventies and Eighties]. Budapest: Noran.

Kumparak, Greg. 2014. "Forgotify Only Plays Spotify Songs That No One Has Ever Played Before." Techcrunch, January 30.

Lee, Steve S., and Richard A. Peterson. 2004. "Internet-Based Virtual Music Scenes: The Case of P2 in Alt. Country Music." In Music Scenes: Local, Translocal and Virtual, edited by Andy Bennett and Richard A. Peterson, 187-204. Nashville: Vanderbilt University Press.

Lessig, Lawrence. 2006. Code: Version 2.0. New York: Basic Books. 
Macdonald, Nancy. 2001. The Graffiti Subculture: Youth, Masculinity and Identity in London and New York. Basingstoke: Palgrave Macmillan.

Magaudda, Paolo. 2020. "Music Scenes as Infrastructures: From Live Venues to Algorithmic Data." In Popular Music, Technology, and the Changing Media Ecosystem, edited by Tamas Tofalvy and Emília Barna, 00-00. Cham: Palgrave Macmillan.

Marvin, Carolyn. 1988. When Old Technologies Were New: Thinking About Electric Communication in the Late Nineteenth Century. Oxford: Oxford University Press.

Matsue, Jennifer Milioto. 2009. Making Music in Japan's Underground: The Tokyo Hardcore Scene. New York: Routledge.

Panuzzo, Barbara Anna. 2010. “The Jump Off': Getting a Taste of the Real Street Flavour? A Critical Analysis of an Underground Hip-Hop Club and Its Logic of Mainstream Authenticity." In Sounds of the Overground: Selected Papers from a Postgraduate Colloquium on Ubiquitous Music and Music in Everyday Life, edited by Nedim Hassan and Holly Tessler, 12-18. Turku, Finland: International Institute for Popular Culture.

Reynolds, Steve. 2009. "The Changing Sound of the Underground." Guardian Music Blog, December 21.

Schaefers, Tobias. 2014. "Standing Out from the Crowd: Niche Product Choice as a Form of Conspicuous Consumption." European Journal of Marketing 48 (9/10): 1805-1827.

Shuker, Roy. 2001. Understanding Popular Music. London: Routledge.

Sterne, Jonathan. 2012. MP3: The Meaning of a Format. Durham: Duke University Press.

Straw, Will. 1991. "Systems of Articulation, Logics of Change: Communities and Scenes in Popular Music." Cultural Studies 5 (3): 368-388.

Sükösd, Miklós. 2012. "Underground Print Culture and Independent Political Communication in Communist Regimes: Samizdat as Typosphere in Central and Eastern Europe from the 1960s to the 1980s." Korean Journal of Communication Studies 20 (5): 61-86.

Szemere, Anna. 2001. Up from the Underground: The Culture of Rock Music in Postsocialist Hungary. University Park: Pennsylvania State University Press.

Thornton, Sarah. 1996. Club Cultures: Music, Media and Subcultural Capital. Middletown: Wesleyan University Press.

Tofalvy, Tamas. 2014. “MySpace Bands' and 'Tagging Wars': Conflicts of Genre, Work Ethic and Media Platforms in an Extreme Music Scene.” First Monday $19(9)$.

Toynbee, Jason. 2000. Making Popular Music: Musicians, Creativity and Institutions. London: Arnold. 
Turner, Fred. 2006. From Counterculture to Cyberculture: Stewart Brand, the Whole Earth Network, and the Rise of Digital Utopianism. Chicago: University of Chicago Press.

Vitos, Botond. 2012. "Discursive Demarcation and Identity Construction in the Czech Psytrance Scene: Experiential Versus Ideological Motivations.” EastBound 3 (1): 1-22.

Webb, Peter. 2007. Exploring the Networked Worlds of Popular Music. New York: Routledge.

Wright, Scott. 2010. "Scene and Heard: Drag." Guardian Music Blog, March 8. Wu, Tim. 2017. The Attention Merchants: The Epic Struggle to Get Inside Our Heads. London: Atlantic Books. 